\title{
Coplanar Waveguide Microwave Sensor for Label-Free Real-Time Glucose Detection
}

\author{
Mustafa SAMEER, Poonam AGARWAL \\ Microsystems Lab, School of Computer and Systems Sciences, Jawaharlal Nehru University, 110067 New Delhi, India \\ mustafa.sameer.ece10@itbhu.ac.in,poonamgoel@mail.jnu.ac.in
}

Submitted May 28, 2018 / Accepted December 30, 2018

\begin{abstract}
In this work, a real-time label-free microwave diagnostic approach using Co-Planar Waveguide (CPW) design has been demonstrated for glucose detection. This mechanism has tremendous potential for the biomedical applications. Here, glucose biosensor is implemented with $50 \Omega$ CPW transmission line, where the centre localized $3 \mathrm{~mm}$ diameter of CPW transmission line has been used for the sensing. Glucose sensor is implemented utilizing low cost multilayer PCB and polymer Poly-Di-Methyl-Siloxane(PDMS) fabrication technology. CPW transmission line is fabricated on FR4 microwave laminate board. To confine the Analyte Under Test (AUT) on the sensing area, PDMS polymer cavity is configured in the centre of CPW transmission line. The electromagnetic interaction with the varying dielectric constant of Glucose:DI water solution results shift in $S_{11}$ parameter, which is closely observed to use as the source of sensing. $C P W$ based glucose sensor is experimentally measured for $S_{11}$ parameter using VNA, with varying glucose concentration range from $0 \mathrm{mg} / \mathrm{ml}$ (only DI water) to $4 \mathrm{mg} / \mathrm{ml}$ with the interval of $1 \mathrm{mg} / \mathrm{ml}$. The measured results showed good sensitivity of $108.4 \mathrm{MHz} / \mathrm{mg} / \mathrm{ml}$ and high accuracy with good linear regression coefficient of 0.9979 .
\end{abstract}

\section{Keywords}

CPW, polymer, microwave sensing, glucose sensor, label-free, real-time, PDMS

\section{Introduction}

Diabetes is a chronic disease which may cause life threatening condition. According to WHO, 422 million adults are suffering from diabetes globally and it is increasing haphazardly [1]. The devastating consequences of human life loss created the need of regular glucose monitoring for diabetic patients. There are many glucose level monitoring systems reported by Vashist [2] which are used in hospitals whereas portable kits have been used for patients monitoring at home [3].
Glucose biosensors have been implemented using various sensing techniques such as electrochemical, optical [4], [5], impedance [6] etc. Electrochemical technique is the oldest one and has been regularly upgraded with new materials such as CNT [7-9] and Graphene [10]. All these diagnostic techniques need skilled manpower, well equipped laboratory set-up, mediator chemicals, and also sample preparation and measurement process is cumbersome and time consuming. Seeing the dreadness of diabetes, several research groups are working on real-time sensing and transduction techniques to measure the glucose level. There are commercially available blood sugar testing kits called glucometer, which work in real-time, but these kits are strip based which causes additional usage cost. Microwave sensing approach created the feasibility of strip free reusable device with real-time sensing without usage cost. Microwave sensing technique utilizes the glucose concentration dependent dielectric constant for glucose level measurements. In literature, various microwave glucose sensor designs have been reported, such as intertwined spiral inductor coupled with an interdigital capacitor structure [11], air bridge structure on rectangular meandered line [12] fabricated on GaAs and theoretical modeling of artificial transmission line section implemented in microstrip technology [13] etc. Li [14] reported Distributed MEMS Transmission Line (DMTL) glucose biosensor on silicon. These devices have been fabricated using MEMS micromachining processes which need clean room and sophisticated equipments which cause high device cost. Therefore, there is need to explore the possibilities of low cost fabrication techniques to reduce the device cost e.g. Mason et al. [15] reported a coplanar sensor fabricated on FR4 for glucose detection AUT.

In this paper, a low cost glucose diagnostic microwave sensor fabricated on FR4 integrated with PDMS polymer cavity to hold the AUT is proposed. PDMS polymer is widely used in the area of microfluidics [16] and bioengineering due to its properties of chemical inertness, viscoelasticity, adhesion to metals, easy to process, biocompatibility etc. The major advantages of proposed design are, it is an integrated system-on-chip glucose biosensor fabricated in-house without using cleanroom and microfabrication process. This paper is organized in six sections, where CPW sensor design 
is discussed under Sec. 2, CPW sensor fabrication and experimental results are discussed under Sec. 3 and Sec. 4 respectively. Results and discussion under Sec. 5, and conclusion under Sec. 6.

\section{CPW Sensor Design}

\subsection{Working Principle}

CPW transmission line is formed on a dielectric substrate with finite ground conductor on both sides of the central signal conductor. CPW supports Quasi-TEM (Transverse Electromagnetic) mode of propagation [17] in which electromagnetic wave (EM) propagates through substrate on the backside and air on the topside. The EM wave propagates on the surface of the centre conductor along the transmission line. In this, localized central part of CPW transmission line is being used as the sensing area. Sensing area is confined in the centre of the $50 \Omega \mathrm{CPW}$ transmission line using PDMS polymer film cavity, as shown in Fig. 1. The AUT is placed on the sensing area of the CPW transmission line. Therefore, EM field interacts with localized air/AUT and PDMS polymer film on the topside and PCB dielectric materials on the backside. Here, AUT is varying concentration of glucose. Therefore EM waves interacts with AUT varying glucose concentration, and dielectric constant decreases on increasing the glucose concentration [18], resulting to peak shift to the higher frequency side [11].

\subsection{Sensor Design}

The $50 \Omega$ CPW transmission line is modeled in MATLAB version 7.10 (R2010a) using the CPW characteristic impedance $\left(Z_{0}\right)$ standard formulae, as given below [17].

$$
\begin{gathered}
Z_{0}=\frac{30 \pi K\left(k_{0}^{\prime}\right)}{\sqrt{\varepsilon_{\mathrm{eff}}} K\left(k_{0}\right)}, \\
\varepsilon_{\mathrm{eff}}=1+\frac{\left(\varepsilon_{\mathrm{r}}-1\right) K\left(k_{1}\right) K\left(k_{0}\right)}{2 K\left(k_{1}^{\prime}\right) K\left(k_{0}^{\prime}\right)}
\end{gathered}
$$

where

$$
\begin{gathered}
k_{0}=\frac{S}{S+2 G}, \\
k_{1}=\frac{\sinh \left(\frac{\pi S}{4 h}\right)}{\sinh \left(\frac{\pi(S+2 G)}{4 h}\right)}, \\
k_{0}^{\prime}=\sqrt{1-k_{0}^{2}}, \\
k_{1}^{\prime}=\sqrt{1-k_{1}^{2}} .
\end{gathered}
$$

In this, equation (1) is for the CPW transmission line in which the effective dielectric constant can be calculated using (2). In (2), $\varepsilon_{\mathrm{r}}$ is the relative permittivity of the backside substrate, $h$ is the substrate height, $S$ is the CPW centre signal conductor width, $G$ is the gap between signal and the ground conductor. Equation (2) is applicable only when there is air on the top side and substrate on the back side of the CPW conductor lines. In our design, CPW conductor lines are partially occupied by air, PDMS and AUT on the top side whereas on the backside there is substrate. Under these circumstances, when top side air has been replaced with other materials, equation (2) has been modified as below equation [17]:

$$
\begin{gathered}
\varepsilon_{\mathrm{eff}}=1+q_{1}\left(\varepsilon_{\mathrm{r}}-1\right)+q_{2}\left(\varepsilon_{\mathrm{r} 1}-1\right), \\
q_{1}=\frac{1 K\left(k_{1}\right) K\left(k_{0}\right)}{2 K\left(k_{1}^{\prime}\right) K\left(k_{0}^{\prime}\right)}, \\
q_{2}=\frac{1 K\left(k_{2}\right) K\left(k_{0}\right)}{2 K\left(k_{2}^{\prime}\right) K\left(k_{0}^{\prime}\right)}, \\
k_{1}=\frac{\sinh \left(\frac{\pi S}{4 h_{1}}\right)}{\sinh \left(\frac{\pi(S+2 G)}{4 h_{1}}\right)}, \\
k_{2}^{\prime}=\sqrt{1-k_{2}^{2}} .
\end{gathered}
$$

Equation (2) is having only one dielectric constant term which is for the backside substrate considering air on the top side, whereas equation (7) includes two dielectric constant terms for both top side and backside dielectric materials of the CPW conductor lines. At the sensing area, $\varepsilon_{\mathrm{r}}$ is the dielectric constant of the backside substrate, and topside films dielectric constant is $\varepsilon_{\mathrm{r} 1}=\left(\varepsilon_{1} h_{1}+\varepsilon_{2} h_{2} /\left(h_{1}+h_{2}\right)\right.$ where $\varepsilon_{1}$ is the dielectric constant of the respective material in the cavity, Air/AUT (as shown in Fig. 1) which is localized, $h_{1}$ is the cavity height, $\varepsilon_{2}$ is the dielectric constant of the PDMS polymer, $h_{2}$ is the thin PDMS polymer film. Dielectric constant of the PDMS layer is constant whereas the dielectric constant of the AUT will vary depending on the glucose concentration in the solution. The variation in AUT dielectric constant $\varepsilon_{\mathrm{r} 1}$ w.r.t. the glucose concentration will cause the change in the characteristic impedance, consequently CPW S-parameters which are being used for the sensing mechanism. The analytically modelled CPW glucose sensor design parameters are listed in Tab. 1, fabrication details are discussed under next section.

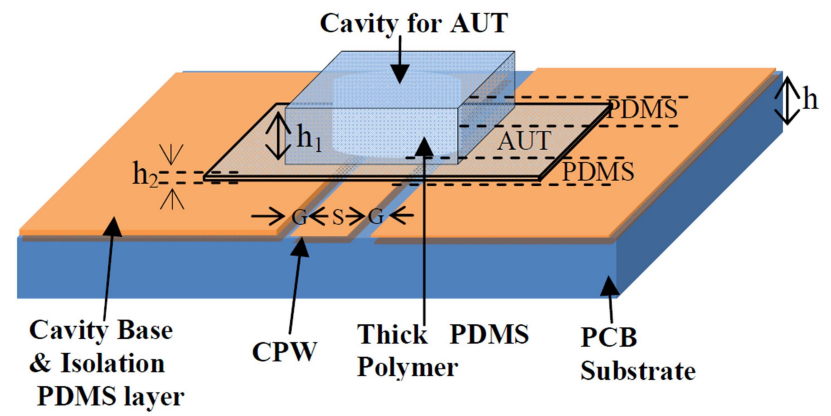

Fig. 1. 3D view of CPW glucose sensor. 


\begin{tabular}{|c|c|}
\hline Design Parameters & Dimensions $(\mathrm{mm})$ \\
\hline Substrate Height $(h)$ & 1.576 \\
\hline CPW Length & 20 \\
\hline CPW $G-S-G$ & $0.34-2-0.34$ \\
\hline Cavity Diameter & 3 \\
\hline Cavity Height & 4 \\
\hline
\end{tabular}

Tab. 1. CPW sensor design parameters.

\section{CPW Sensor Fabrication}

Micromachined glucose sensor with design parameters listed in Tab. 1, is fabricated using PCB and PDMS polymer multilayer fabrication processes. $50 \Omega \mathrm{CPW}$ transmission line is fabricated on FR4 substrate, whereas cavity to confine the AUT to the sensing area is fabricated using PDMS polymer as discussed below:

CPW transmission line fabrication- Commercially available FR4 board with both side copper clad of $35 \mu \mathrm{m}$ thickness is used as the substrate. CPW transmission line Ground-Signal-Ground (GSG) conductors with dimensions listed in Tab. 1, are patterned on one side and copper is completely etched away from the backside of PCB. The CPW design parameters G-S-G $0.34 \mathrm{~mm}-2 \mathrm{~mm}-0.34 \mathrm{~mm}$ has been used to fabricate $50 \Omega$ transmission line.

Formation of the Cavity to hold AUT- The cavity is formed of PDMS polymer layers using Dow Corning Sylgard 184 kit. In Dow Corning Sylgard 184 kit, PDMS base and curing agent are taken in the ratio of $10: 1$ by weight. Then whisked thoroughly with a stirrer for 10 minutes, to mix the curing agent uniformly. PDMS polymer layers are cured by keeping still for 48 hours at room temperature. Through hole of diameter $3 \mathrm{~mm}$ is formed in the thick PDMS layer using surgical biopsy punch.

Device Assembling: Device is assembled by configuring the cavity on the CPW transmission line. Cavity is formed by fixing the through hole thick PDMS layer with underneath thin layer PDMS on the CPW transmission line. The fabricated device is measured for the RF performance, experimental set-up details are discussed next.

\section{Experimental Setup}

The fabricated CPW Glucose sensor is measured for RF performance using Rohde \& Schwarz ZNB20 Vector Network Analyzer (VNA). Experimental set-up of the CPW glucose sensor is shown in Fig. 2(a), whereas close-up view of DUT is shown in Fig. 2(b). D-glucose $\left(\mathrm{C}_{6} \mathrm{H}_{12} \mathrm{O}_{6}\right)$ :DI water solution of concentrations $0 \mathrm{mg} / \mathrm{ml}, 1 \mathrm{mg} / \mathrm{ml}, 2 \mathrm{mg} / \mathrm{ml}$, $3 \mathrm{mg} / \mathrm{ml}$ and $4 \mathrm{mg} / \mathrm{ml}$ had been prepared. AUT of $20 \mu \mathrm{l}$ volume was dropped using micropipette in the cavity. RF measurements are carried out with all these glucose concentrations are measured in sequence. The cavity is thoroughly cleaned with water after each measurement and gets it completely dry before reuse. Measurements are carried out under $20.3^{\circ} \mathrm{C}$ temperature and $52 \%$ humidity. Measured result has been presented in the next section.

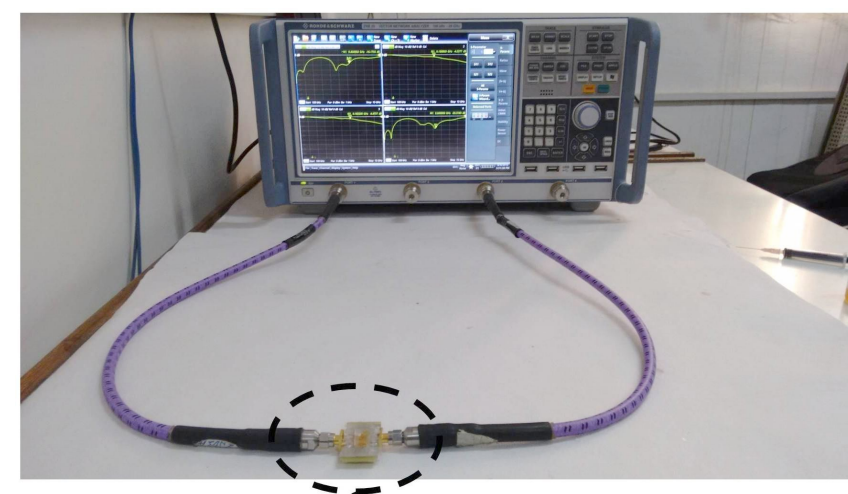

(a)

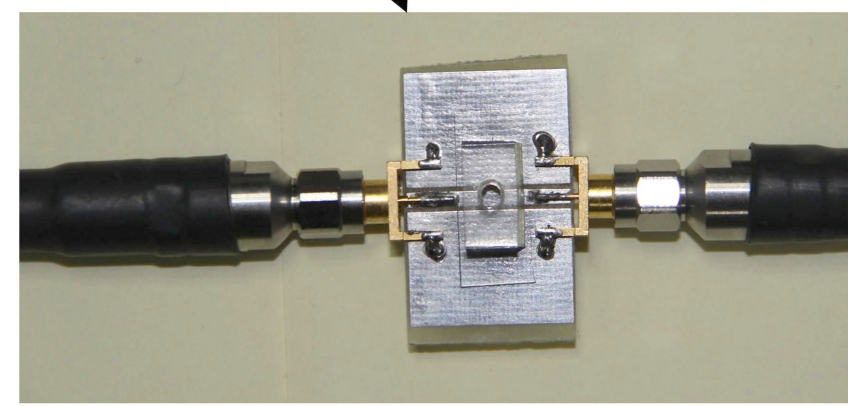

(b)

Fig. 2. (a) Experimental set-up of glucose sensor, (b) close-up view of the device under test.

\section{Experimental Results and Discussion}

\subsection{Experimental Results}

CPW glucose sensor is experimentally measured for the reflection coefficient $S_{11}$ parameters with varying glucose concentration. The measured $S_{11}$ parameter of CPW, microwave biosensor with air cavity and for glucose concentration ranging from $0 \mathrm{mg} / \mathrm{ml}$ to $4 \mathrm{mg} / \mathrm{ml}$ with the interval of $1 \mathrm{mg} / \mathrm{ml}$ as listed in Tab. 2. RF Measurements carried out for CPW (without any PDMS layers) showed peak frequency $3.6 \mathrm{GHz}$, which shifted to $3.236 \mathrm{GHz}$ for assembled device (air cavity). The shift is due to high dielectric constant 2.8 of PDMS polymer compared to the air dielectric constant 1 . The shifted peak frequency for air cavity, $0 \mathrm{mg} / \mathrm{ml}, 1 \mathrm{mg} / \mathrm{ml}, 2 \mathrm{mg} / \mathrm{ml}, 3 \mathrm{mg} / \mathrm{ml}$ and $4 \mathrm{mg} / \mathrm{ml}$ is $3.236,2.519,2.636,2.753,2.856$ and $2.951 \mathrm{GHz}$ respectively listed in Tab. 2. The measured peak frequency shifts toward high frequency as the glucose concentration is increased (as shown in Fig. 3), which is due to decrease in the dielectric constant on increasing the glucose concentration. The experimentally measured plot Fig. 3 showed $S_{11}$ peak gets sharper on decreasing the glucose concentration which is because of decrease in loss factor with decrease in the glucose concentration in the solution [11]. The RF measurements are carried out in $<10$ s time span to avoid any substantial temperature 
variation of the solution during the measurements. The regression analysis presents the glucose concentration w.r.t. peak frequency, which is linear with curve fitting (as shown in Fig. 4), and actual values are exactly in the linear curve a good linear correlation $\left(R^{2}=0.9979\right)$ between glucose concentration and shift in centre frequency with a linear regression equation expressed as follows. Hence, measured device sensitivity is $108.4 \mathrm{MHz} / \mathrm{mg} / \mathrm{ml}$ with good linear correlation of 0.9979 .

$$
\begin{gathered}
y=0.108 x+2.526, \\
R^{2}=0.997 .
\end{gathered}
$$

\begin{tabular}{|c|c|}
\hline Glucose concentration $(\mathrm{mg} / \mathrm{ml})$ & Peak Frequency $f(\mathrm{GHz})$ \\
\hline CPW (without PDMS layer) & 3.6 \\
\hline CPW with cavity on the top & 3.236 \\
\hline 0 & 2.519 \\
\hline 1 & 2.636 \\
\hline 2 & 2.753 \\
\hline 3 & 2.856 \\
\hline 4 & 2.951 \\
\hline
\end{tabular}

Tab. 2. Measured peak frequency w.r.t. the glucose concentration.

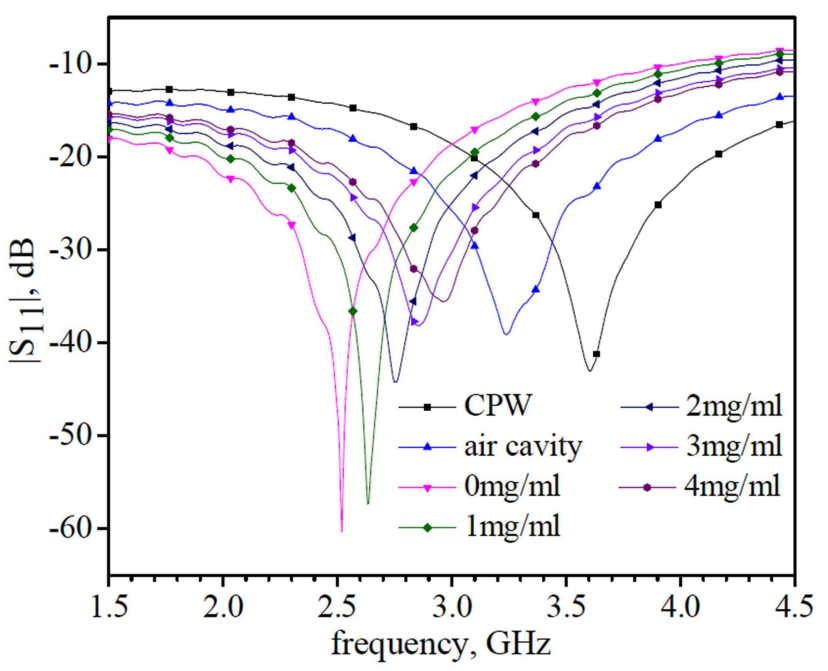

Fig. 3. Shift in the peak frequency and the variations in $S_{11}$ magnitude for the glucose samples of varying concentrations.

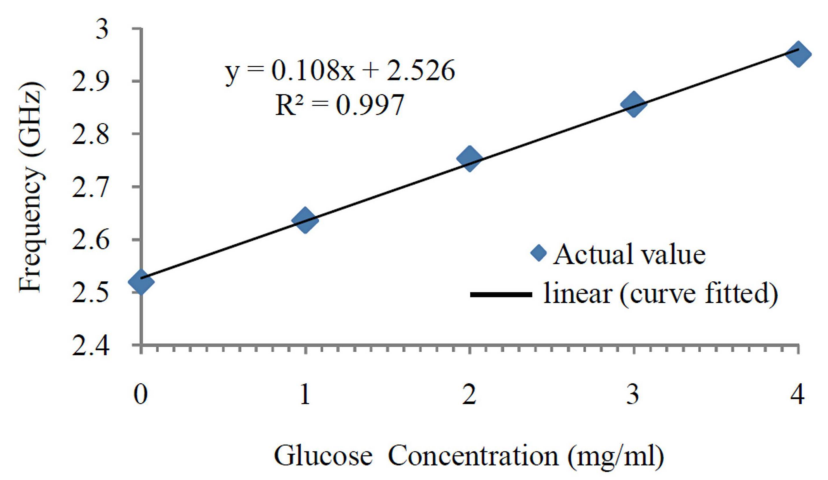

Fig. 4. Comparison in linearly curve fitted peak frequencies with the actual peak frequencies.

\subsection{Discussions}

A comparison of our proposed CPW planar glucose sensor with the ring resonator based glucose sensor reported by Camli et al. [19] on the basis of various aspects, such as performance, design, fabrication, and measurements as listed in Tab. 3, which shows our proposed glucose sensor is with very high sensitivity of $108.4 \mathrm{MHz} / \mathrm{mg} / \mathrm{ml}$ compared to $0.107 \mathrm{MHz} / \mathrm{mg} / \mathrm{ml}$ [19], very high linear correlation 0.9979 compared to 0.79 [19]. Sample requirement in this proposed work is only $20 \mu \mathrm{l}$ compared to $90 \mu \mathrm{l}$ [19] in the literature. The device reported in literature [19] needs a laser cutter to make the cavity to confine the AUT, whereas the proposed CPW glucose sensor is easy to design and is fabricated in-house.

\begin{tabular}{|l|l|l|}
\hline Parameters & Ref [19] & Our Work \\
\hline $\begin{array}{l}\text { Sensitivity } \\
(\mathrm{MHz} / \mathrm{mg} / \mathrm{mL})\end{array}$ & 0.107 & 108.4 \\
\hline $\begin{array}{l}\text { Linear correlation } \\
\left(R^{2}\right)\end{array}$ & 0.79 & 0.9979 \\
\hline Sample value $(\mu \mathrm{l})$ & 90 & 20 \\
\hline Substrate used & FR4 & FR4 \\
\hline $\begin{array}{l}\text { Fabrication Tech- } \\
\text { nique }\end{array}$ & $\begin{array}{l}\text { PCB AUT holder: } \\
\text { Reservoir formed } \\
\text { by Laser Cutter }\end{array}$ & $\begin{array}{l}\text { PCB technology } \\
\text { AUT Holder: } \\
\text { PDMS Polymer } \\
\text { Process, Surgical } \\
\text { Biopsy Punch } \\
\text { was used to create } \\
\text { cavity }\end{array}$ \\
\hline $\begin{array}{l}\text { Design } \\
\text { plexity }\end{array}$ & $\begin{array}{l}\text { Spilt ring Res- } \\
\text { onator Based }\end{array}$ & CPW Planar \\
\hline Design Complexity & Medium & Low \\
\hline $\begin{array}{l}\text { Measurement Pro- } \\
\text { cess Complexity }\end{array}$ & High & Low \\
\hline Overall Device Cost & Medium & Lery Low \\
\hline
\end{tabular}

Tab. 3. Proposed device compared with the reported [19].

\section{Conclusion}

In this paper, a portable real-time and label-free glucose diagnostic approach based on microwave sensing technique is demonstrated using a low cost PCB and PDMS Polymer fabrication technology. The demonstrated device is fabricated without using any cleanroom processes. Proposed microwave sensing device is a strip free reusable sensor. The proposed device is with high sensitivity, good accuracy and easy to fabricate compared to the reported in literature.

\section{Acknowledgments}

We would like to acknowledge Department of Science \& Technology (DST), Govt. of India to support this work under "DST INSPIRE Faculty Award Research Grant (IFA12-ENG-24)", DST PURSE research grant. We also 
thank UGC and JNU for financial support under UGC UPE-II JNU, project ID-64. We would like to thank USIC JNU for helping in workshop jobs. We would like to thank Amit Sharma for helping in preparing the manuscript.

\section{References}

[1] World Health Organization. [Online] Cited 2018-05-01. Available at http://www.who.int/diabetes/en/

[2] VASHIST, S. K. Continuous glucose monitoring systems: A review. Diagnostics, 2013, vol. 3, no. 4, p. 385-412. DOI: 10.3390/diagnostics3040385

[3] NEWMAN, J. D., TURNER, A. P. F. Home blood glucose biosensors: a commercial perspective. Biosensors and Bioelectronics, 2005, vol. 20, no. 12, p. 2453-2453. DOI: 10.1016/j.bios.2004.11.012

[4] ALORAEF, M., PFEFER, T. J., RAMELLA-ROMAN, J. C., SAPSFORD, K. E. In vitro evaluation of fluorescence glucose biosensor response. Sensors, 2014, vol. 14, no. 7, p. 12127-12148. DOI: $10.3390 / \mathrm{s} 140712127$

[5] OZANA, N., ARBEL, N., BEIDERMAN, Y., et al. Improved noncontact optical sensor for detection of glucose concentration and indication of dehydration level. Biomedical Optics Express, 2014, vol. 5, no. 6, p. 1926-1940. DOI: 10.1364/BOE.5.001926

[6] PRADHAN, R., MITRA, A., DAS, S. Quantitative evaluation of blood glucose concentration using impedance sensing devices. Journal of Electrical Bioimpedance, 2013, vol. 4, no. 1, p. 73-77. DOI: $10.5617 /$ jeb. 657

[7] HARPER, A., ANDERSON, M. R. Electrochemical glucose sensorsdevelopments using electrostatic assembly and carbon nanotubes for biosensor construction. Sensors, 2010, vol. 10, no. 9, p. 8248-8274. DOI: $10.3390 / \mathrm{s} 100908248$

[8] VARGHESE, S .H., YOSHIDA, Y., MAEKAWA, T., et al. Enhancement of glucose sensing behaviour of Cobalt tetraphenylporphyrin thin film using single wall CNT. Sensors and Materials, 2011, vol. 23, no. 6, p. 335-345. DOI: 10.18494/SAM.2011.724

[9] WANG, W., YIN, G., MA, X., WAN, J. Simple method for preparing glucose biosensor based on glucose oxidase in nanocomposite material of single-wall carbon nanotubes/ionic liquid. Journal of Analytical Sciences, Methods and Instrumentation, 2012, vol. 2, no. 2, p. 54-59. DOI: 10.4236/jasmi.2012.22011

[10] JIANG, D., LIU, Q., WANG, K., et al. Enhanced non-enzymatic glucose sensing based on copper nanoparticles decorated nitrogen-doped graphene. Biosensors and Bioelectronics, 2014, vol. 54, p. 273-278. DOI: 10.1016/j.bios.2013.11.005

[11] KIM, N. Y., ADHIKARI, K. K., DHAKAL, R., et al. Rapid, sensitive, and reusable detection of glucose by a robust radiofrequency integrated passive device biosensor chip. Scientific Reports, 2015, vol. 5, no. 1, p. 1-9. DOI: $10.1038 /$ srep07807

[12] KIM, N. Y., DHAKAL, R., ADHIKARI, K. K., et al. A reusable robust radio frequency biosensor using microwave resonator by integrated passive device technology for quantitative detection of glucose level. Biosensors and Bioelectronics, 2015, vol. 67, p. 687-693. DOI: 10.1016/j.bios.2014.10.021
[13] VRBA, J., VRBA, D. A. Microwave metamaterial inspired sensor for non-invasive blood glucose monitoring. Radioengineering, 2015, vol. 24 , no. 4, p. 877-884. DOI: 10.13164/re.2015.0877

[14] LI, L. J. Simultaneous detection of organic and inorganic substances in a mixed aqueous solution using a microwave dielectric sensor. Progress in Electromagnetics Research C, 2010, vol. 14, p. 163-171. DOI: 10.2528/PIERC10051308

[15] MASON, A., KOROSTYNSKA, O., ORTONEDA-PEDROLA, M., et al. A resonant co-planar sensor at microwave frequencies for biomedical applications. Sensors and Actuators A (Physical), 2013, vol. 202, p. 170-175. DOI: 10.1016/j.sna.2013.04.015

[16] NG, J. L., SHIN, Y., CHUNG, S. Microfluidic platforms for the study of cancer metastasis. Biomedical Engineering Letters, 2012, vol. 2, no. 2 , p. $72-77$. DOI: $10.1007 / \mathrm{s} 13534-012-0055-\mathrm{x}$

[17] SIMONS, R. N. Coplanar Waveguide Circuits, Components and Systems. New York: Wiley \& Sons, 2001. ISBN: 9780471161219

[18] MALMERG, C. G., MARYOTT, A. A. Dielectric constants of aqueous solutions of dextrose and sucrose. Journal of Research of the National Bureau of Standards, 1950, vol. 45, no. 4, p. 299-303. DOI: $10.6028 /$ jres.045.030

[19] CAMLI, B., KUSAKCI, E., LAFCI, B., et al. Cost-effective, microstrip antenna driven ring resonator microwave biosensor for biospecific detection of glucose. IEEE Journal of Selected Topics in Quantum Electronics, 2017, vol. 23, no. 2, p. 404-409. DOI: $10.1109 /$ JSTQE.2017.2659226

\section{About the Authors...}

Mustafa SAMEER received his M.Tech Degree in Electronics Engineering from Indian Institute of Technology, Banaras Hindu University, Varanasi in 2012. He worked as Research Assistant in School of Computer and System Sciences, Jawaharlal Nehru University, New Delhi. His research interests include BioMEMS, low power VLSI Design, electromagnetic sensors. He is an Associate member of Institution of Electronics and Telecommunication Engineers (IETE), New Delhi.

Poonam AGARWAL is M.Tech from Panjab University, Chandigarh and $\mathrm{PhD}$ from Indian Institute of Science, Bangalore. She worked as post-doctoral researcher at Nanyang Technological University Singapore. Currently, she is working as Assistant Professor in School of Computer and Systems Sciences, Jawaharlal Nehru University, New Delhi. She is DST INSPIRE Faculty awardee, by Department of Science \& Technology, Govt. of India. Her main research interests are focused on unconventional polymer fabrication techniques for meso-scale electro-mechanical systems for phased array antenna systems, energy harvester, and microwave biosensor. 